\title{
Evaluation of a new adipose tissue processing method for breast and buttock fat grafting procedures
}

\author{
Eric Auclair ${ }^{1} \cdot$ Massimo Gianfermi ${ }^{2,3}$ \\ Received: 31 May 2020 / Accepted: 9 September 2020 / Published online: 26 September 2020 \\ (C) The Author(s) 2020
}

\begin{abstract}
Background There is still some debate about the best adipose processing method for autologous fat transfer procedures. This article reports a series of 66 fat grafting procedures using a novel fat processing technique that involves washing, "micronization," and decantation.

Methods We retrospectively reviewed the files of all patients operated on over a 2-year period by the two investigators. They underwent breast or buttock surgery that employed the novel fat processing technique for fat transfer. Complications and patient satisfaction were recorded, and fat resorption was qualitatively assessed based on clinical examination and photographs.

Results Data were retrieved from a total of 66 procedures performed on 43 patients: 17 breast augmentations, 8 buttock augmentations, and 41 breast reconstructions. Five patients also underwent concomitant facial fat grafting. The complications were one case of transient liponecrotic cyst in the breast, one case of transient areolar sensitivity reduction, and two cases of infection. The infections were reported in patients from the breast reconstruction cohort who had a history of radiotherapy. There was no complication associated with facial fat grafting. Patient satisfaction was achieved in 82.4 to $92.5 \%$ of cases depending on the study cohort. Fat resorption was graded as minimal to moderate in $95 \%$ of all cases.

Conclusions This retrospective study supports the safety and effectiveness of this novel fat processing method in breast and buttock surgeries. Further controlled studies are needed to compare its performance with that of other techniques.

Level of evidence: Level III, therapeutic study
\end{abstract}

Keywords Lipofilling $\cdot$ Fat grafting $\cdot$ Breast reconstruction $\cdot$ Buttock fat grafting $\cdot$ Fat processing $\cdot$ Adipose tissue $\cdot$ Brazilian butt lift · Autologous fat grafting

\section{Introduction}

Fat grafting to the breast or buttocks, by itself or in combination with silicone implants, has become popular among plastic surgeons over the past decade. Autologous transfer of adipose tissue was first described in 1893 by Neuber [1], but it was Coleman who

Massimo Gianfermi

1 Clinique Nescens Paris Spontini, 68 bis rue Spontini, 75116 Paris, France

2 Centre Hospitalier Simone Veil de Beauvais, 40 Avenue Léon Blum, 60000 Beauvais, France

3 Clinique du Louvre, 17 Rue des Prêtres Saint-Germain l'Auxerrois, 75001 Paris, France popularized it a century later with his "lipostructure" technique [2]. There have been recent concerns in the scientific community regarding the oncological safety of fat grafting, and its potential interference with breast cancer screening. However, a significant number of clinical studies have now shown that fat grafting is not associated with a significant oncological risk [3, 4]. Furthermore, it has now been established that fat grafting does not lead to missed or incorrect breast cancer diagnoses [3].

Numerous techniques for fat processing have been described and evaluated, including centrifugation, cotton gauze rolling, sedimentation, and filtration/washing [5]. A common goal of these techniques is to purify the fat in order to lower fat resorption as much as possible. The reported fat resorption rate varies between 20 and $80 \%$ of the total injected volume [5]. Despite the considerable number of clinical studies on the topic, there 
is no real consensus about the most efficient way to process fat to achieve optimal results [5]. While fat centrifugation, as proposed by Coleman, was shown to be linked to lower adipocyte viability [6] and more complications [7], specifically fat necrosis [8], there is still debate about the superiority of the other available techniques in terms of safety and effectiveness [5, 7-10]. In this study, we focus on a new fat processing technique that involves adipose tissue washing, "micronization," and decantation. This technique has been reported in a few studies in the scientific literature $[11,12]$, but, to the best of our knowledge, no study on its safety and effectiveness in a sufficiently large patient series has been published so far.

The aim of this retrospective study was, thus, to evaluate this novel fat processing technique in a series of patients who underwent breast or buttock fat grafting procedures.

\section{Patients and methods}

\section{Patients and study cohorts}

This retrospective study included patients who were of legal age under French law ( $\geq 18$ years), who were operated on by the investigators between May 2017 and June 2019. The patients underwent breast or buttock fat grafting with the novel fat processing technique, and they were included after they had been given information about the study and had provided their oral consent for the use of their data. The exclusion criteria were composite breast or buttock augmentation (i.e., with concomitant use of silicone implants); ongoing pregnancy or breastfeeding; known autoimmune disease; and inability of the patient to understand the concept of the study and thus to provide informed oral consent. No ethics committee approval was required to conduct this retrospective study. As required by French law, the study was registered with the National Institute of Health Data registry (Institut National des Données de Santé in French).

\section{Novel adipose processing procedure}

The Fat Washer 800 device (Groupe SEBBIN, Boissy l'Aillerie, France) was used for harvesting and processing the adipose tissue, through a combination of washing, "micronization," and decantation. In this procedure, first, the adipose tissue is aspirated together with saline solution with the help of a Y-connector located under the harvesting canula (Fig. 1).

The adipose tissue aspirated through a multi-hole canula is thus mixed with saline solution coming from a bag of saline. The saline solution, circulating more rapidly than the adipose tissue in the tubing, provides a first washing of the fatty tissue (Fig. 2).

After the aspirated material is decanted, the subnatant fluid is removed from the canister through a dedicated tubing and saline is added to the fat in the canister. Next, air is aspirated from the bottom of the device through an antimicrobial $0.2-\mu \mathrm{m}$ filter. This creates a slight whirl in the canister, which allows completion of washing of the fat (Fig. 2). The name given to this step of the processing, "micronization," suggests that it decreases lobule size. We did not quantitatively check this claim in our study. However, in our experience, as a qualitative evaluation, the adipose tissue seems to be easier to inject through a thin canula when this "micronization" step is performed.
Fig. 1 Tubing with Y-connector allowing for simultaneous aspiration of fat and saline solution

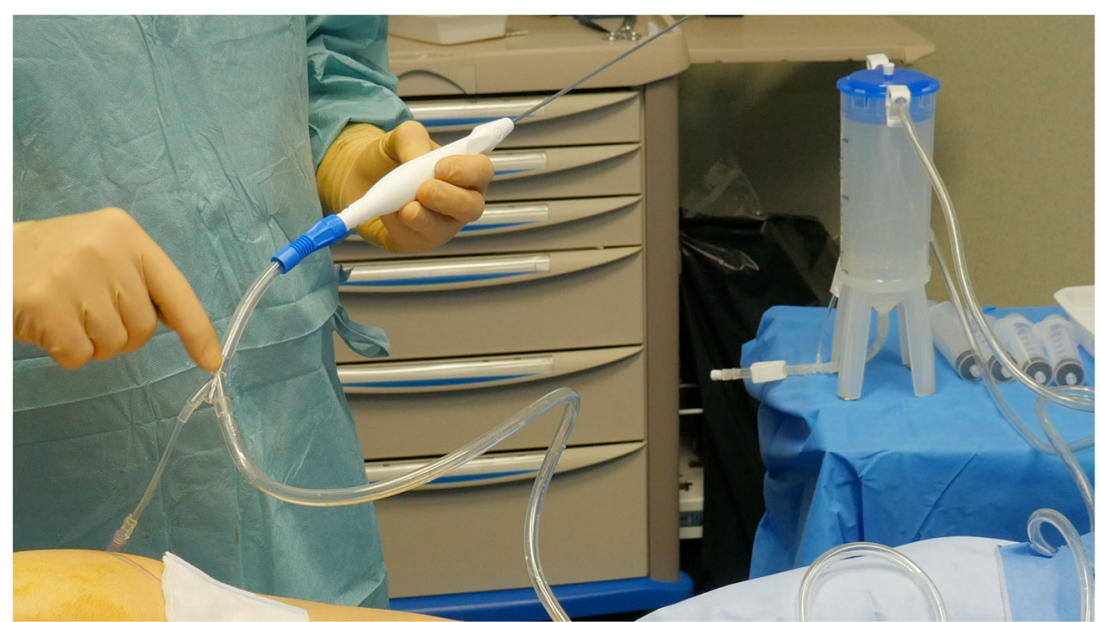


After the solution is decanted, the saline is removed using the dedicated tubing and the purified fat is collected in 10-cc syringes (Fig. 2). All manipulations (saline solution addition, removal, "micronization," and so on) are done using the depression in the canister by opening and closing clamps located on the different tubes, thus avoiding any manipulation of the graft in the open air.

\section{Data collection and analysis}

Patient data and data related to the procedure were recorded in patient files by the investigators, who subsequently filed electronic case report forms. All complications related to the procedure, as well as the fat resorption rate and patient satisfaction, as reported by the surgeon, were recorded. Fat resorption was evaluated based on the findings of clinical examination and photographs, with the help of a qualitative scale, according to which the resorption was graded as invisible, minimal, moderate, significant, or total. Complications were calculated using absolute rates associated with the procedure. Statistical analysis was performed using Medcalc software (Mariakerke, Belgium).

\section{Results}

\section{Demographic and clinical information}

A total of 43 patients, all female, were included in this study: 17 patients comprised the breast augmentation
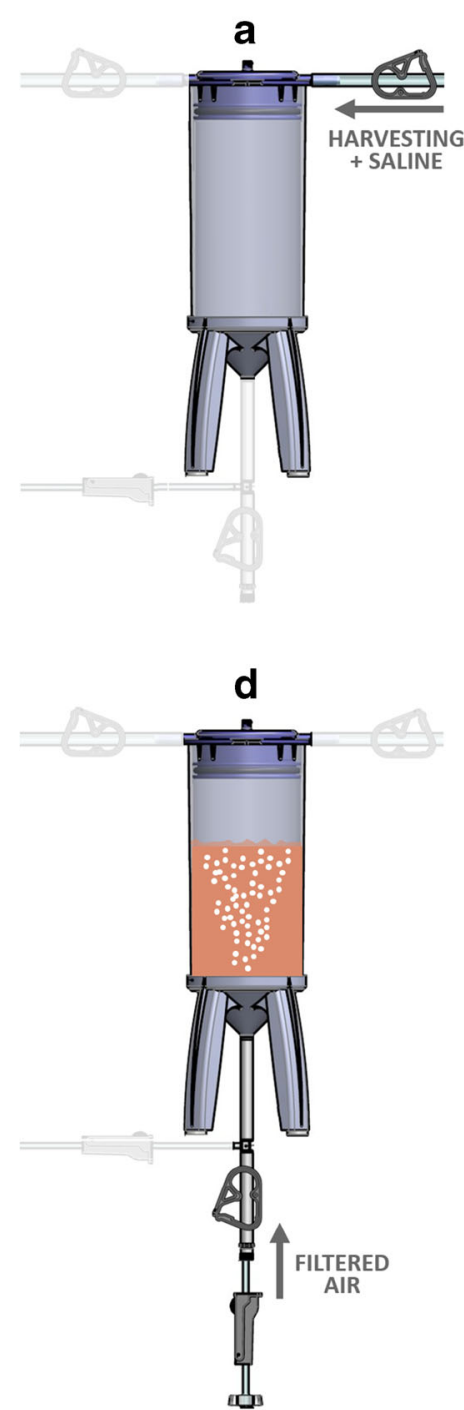
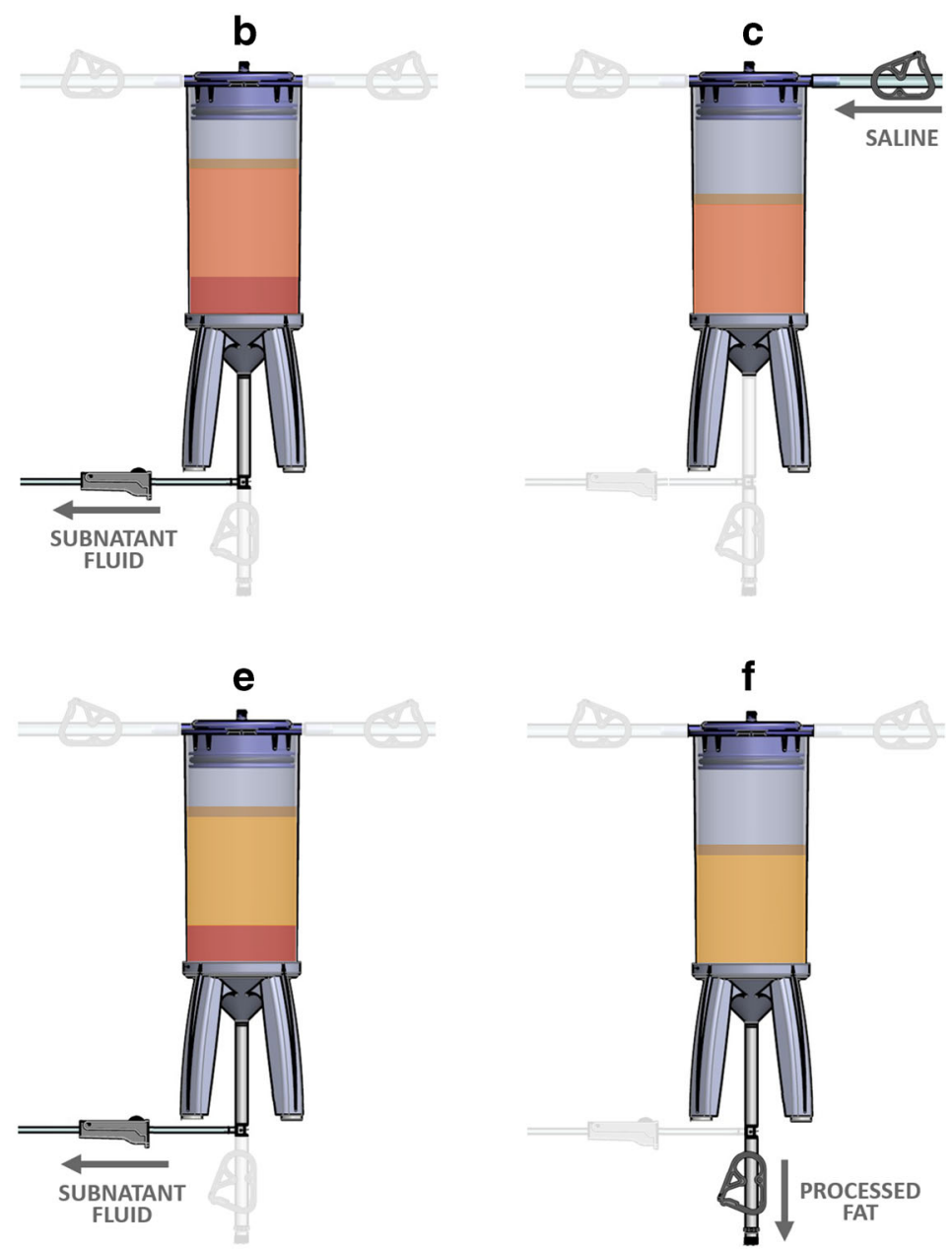

Fig. 2 Steps of the fat processing technique. a Simultaneous harvesting of fat and saline. b Subnatant fluid removal. $\mathbf{c}$ Addition of new saline. $\mathbf{d}$ "Micronization." e Subnatant fluid removal. f Collection of processed fat in syringes 
Fig. 3 Breast augmentation case. Preoperative picture and outcome after one session of fat grafting

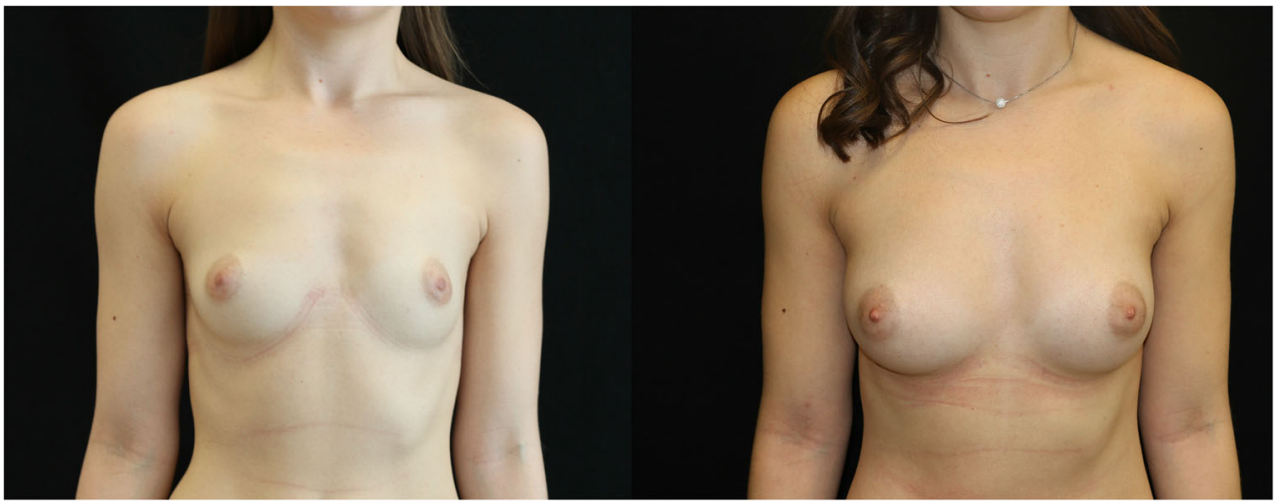

cohort; 8 patients, the buttock augmentation cohort; and 24 patients, the breast reconstruction cohort. Six patients underwent both breast and buttock augmentation, and, therefore, they were included in the breast augmentation and buttock augmentation cohorts.

In the breast augmentation cohort, eight patients underwent fat grafting for cosmetic breast augmentation; two had previously undergone implant-based augmentation that required refinement; two wanted to have their implants removed and replaced with adipose tissue; three presented with breast ptosis; two presented with asymmetry; one presented with tuberous breast; and one needed breast correction after extensive weight loss. Two of the patients presented with two combined indications each.

In the reconstruction cohort, all the patients had a history of breast cancer. Among them, $75.0 \%$ had a history of total mastectomy, and $25.0 \%$ had a history of lumpectomy. The fat grafting procedure was unilateral in $79.2 \%$ of cases and bilateral in $20.8 \%$ of cases. In this cohort, $79.2 \%$ of patients had a history of radiotherapy. Furthermore, $29.2 \%$ of the patients already had expander or definitive implants in place, $20.8 \%$ had undergone previous reconstruction with a flap, and $25.0 \%$ had already undergone fat grafting (by another technique).

Two cases are depicted in Figs. 3 and 4.

\section{Procedure-related information}

The average patient follow-up of the overall population was 7.1 months.

All fat grafting surgeries were performed under general anesthesia. Antibioprophylaxis was administered to $88.2 \%$ of the breast augmentation patients, $100 \%$ of the buttock augmentation patients, and $4.2 \%$ of the breast reconstruction patients. No systematic postoperative oral antibiotic treatment was prescribed in any of the cases. The most common donor sites were the abdomen, the flanks, and the inner and outer thighs. There were no preoperative complications. Infiltration was performed in all cases with saline solution and adrenaline. No local anesthetics were used for the infiltration procedures.

In all the breast and buttock augmentation patients, only one session of fat grafting was performed during the study period. In the breast reconstruction patients, an average of 1.7 (range, 1-4) fat grafting sessions

Fig. 4 Breast reconstruction case. Preoperative picture and outcome after three sessions of fat grafting

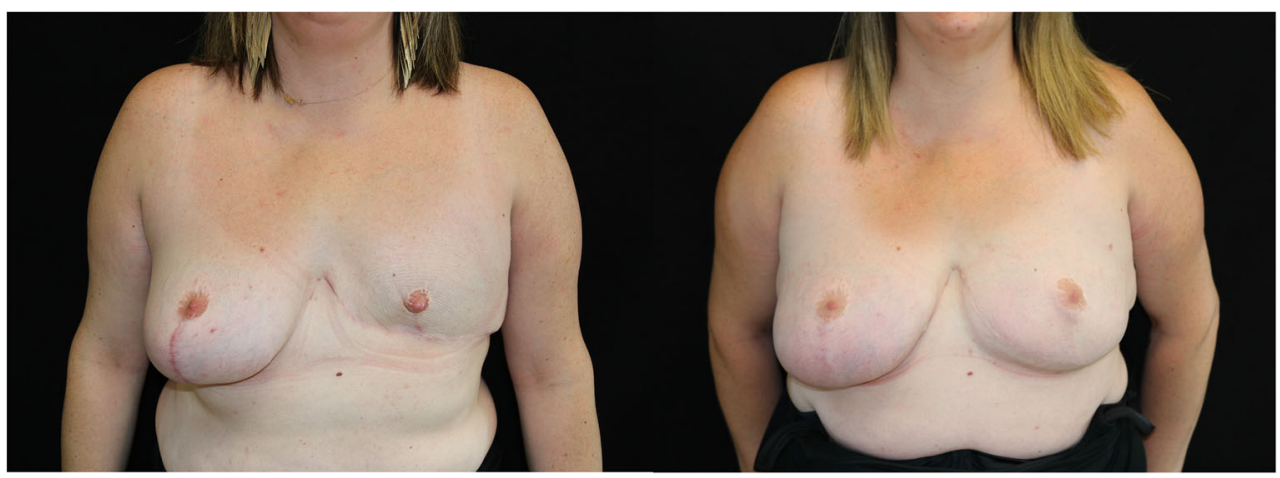


Table 1 Demographic and surgical data

\begin{tabular}{llll}
\hline & $\begin{array}{l}\text { Breast } \\
\text { augmentation }\end{array}$ & $\begin{array}{l}\text { Buttock } \\
\text { augmentation }\end{array}$ & $\begin{array}{l}\text { Breast } \\
\text { reconstruction }\end{array}$ \\
\hline Number of patients & 17 & 8 & 24 \\
Age, years, mean (SD) & $37.4(9.7)$ & $34.3(9.4)$ & $50.8(7.2)$ \\
BMI, kg $/ \mathrm{m}^{2}$, mean (SD) & $20.3(2.2)$ & $20.0(1.4)$ & $29.8(6.6)$ \\
Smoker, \% & $0 \%$ & $0 \%$ & $25.0 \%$ \\
Total number of fat grafting sessions & 17 & 8 & 41 \\
Volume harvested, ml, mean (SD) & $1205(720)$ & $1350(552)$ & $704(355)$ \\
Volume injected, ml per side, mean (SD) & $238(93)$ & $171(114)$ & $249(123)$ \\
$\begin{array}{l}\text { Follow-up, months, median (range) } \\
\text { (calculated from the first fat grafting }\end{array}$ & $6.5(0.9-22.7)$ & $7.2(3.9-22.7)$ & $7.7(0.3-20.4)$ \\
$\quad$ & & & \\
\hline
\end{tabular}

was performed per patient during the study period. The present study thus reports a series of 66 fat grafting procedures that were performed using this novel technique. Table 1 reports demographic and surgical data.

Five patients from the breast augmentation and/or buttock augmentation cohorts had concomitant cosmetic fat grafting to the face (using the same adipose tissue as injected in the breast and/or buttock). The other concomitant procedures in these cohorts included breast plasty (four cases), rhinoplasty (one case), hyaluronic acid injection (one case), and blepharoplasty (one case).

In the breast reconstruction cohort, the concomitant procedures included breast plasty (seven cases), scar revision (two cases), rhizotomy (two cases), nipple reconstruction (two cases), flap revision (one case), and implantable chamber removal (one case).

\section{Complications and outcome}

A total of four complications (6.1\%) that were linked, or potentially linked, to the fat grafting procedure were reported. Complications in the breast augmentation cohort were transient liponecrotic cyst (one case) and transient areolar sensitivity reduction (one case). In the breast reconstruction cohort, there were two cases of infection. Both patients had a history of radiotherapy and one had undergone concomitant scar revision. Both patients were successfully treated with oral antibiotics, and the reconstruction was not compromised. Table 2 reports all the complications of the patients in the study cohorts.

As expected, some resorption was observed in all the patients. However, the resorption was described as "minimal" to "moderate" in most cases (Fig. 5). Under-correction was reported in four patients of the breast augmentation or buttock augmentation cohort.

Among the breast augmentation cohort, $82.4 \%$ of patients were satisfied to very satisfied with the outcome after a unique session of fat grafting; in the buttock augmentation cohort, the figure was $87.5 \%$. Further, $92.5 \%$ of the reconstruction cohort patients were satisfied to very satisfied after an average of 1.7 fat grafting sessions.

\section{Discussion}

We report here the use of a novel adipose processing protocol, involving fat washing, "micronization," and decantation, on a series of 43 patients who were
Table 2 Rates of complications linked, or potentially linked, to the fat grafting procedure

\begin{tabular}{|c|c|c|c|}
\hline & $\begin{array}{l}\text { Breast augmentation } \\
\text { and/or } \\
\text { reconstruction } \\
\text { No. of cases (\% } \\
\text { of total procedures) }\end{array}$ & $\begin{array}{l}\text { Breast } \\
\text { reconstruction } \\
\text { No. of cases (\% } \\
\text { of total procedures) }\end{array}$ & $\begin{array}{l}\text { Overall } \\
\text { No. of cases } \\
\text { (\% of total } \\
\text { procedures) }\end{array}$ \\
\hline Oil cyst & $1(5.3 \%)$ & $0 \%$ & $1(1.5 \%)$ \\
\hline $\begin{array}{l}\text { Transitory areolar sensitivity } \\
\text { reduction }\end{array}$ & $1(5.3 \%)$ & - & $1(1.5 \%)$ \\
\hline Infection & $0 \%$ & $2(4.9 \%)$ & $2(3.0 \%)$ \\
\hline
\end{tabular}




\section{BREAST \\ AUGMENTATION}

- Invisible
Minimal
Moderate
Significant
- Total

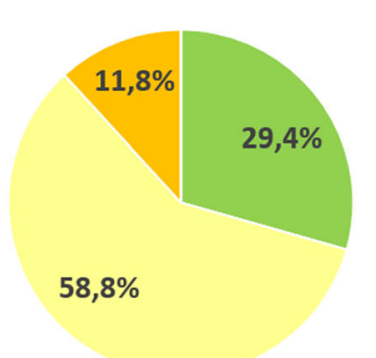

BUTTOCK

AUGMENTATION

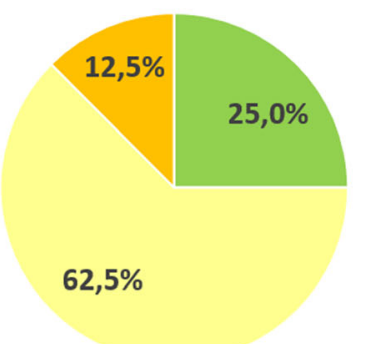

BREAST

RECONSTRUCTION

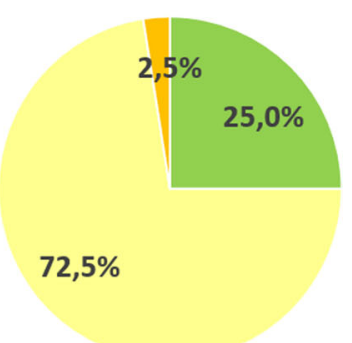

Fig. 5 Qualitative evaluation of fat resorption

undergoing breast/buttock augmentation procedures. Although the use of this technique has already been reported in the buttock [11] and lower extremities [12], to the best of our knowledge, no study has evaluated its safety and effectiveness in breast surgery.

In breast surgery, one of the main goals of the fat processing technique is to reduce as much as possible the oily fraction in the graft in order to lower the risk of complications such as oil cysts and calcification [13]. Fat processing techniques particularly oriented to minimization of the oily fraction have been described [14]. In the technique used in the present study, the oily phase, located after decantation in the superior part of the canister, was discarded. In breast augmentation or reconstruction, high-density fat is often required to achieve a predictable and reliable outcome. In the technique we used here, fat graft density was correlated with decantation time; a longer decantation time led to a higher fat graft density, with a side effect being an increase in surgical time. When highdensity fat is required, an option to reduce waiting time is to use the fat located in the superior part of the canister, just below the oily phase.

In gluteal augmentation, in contrast, the possible formation of oil cysts or calcification should be limited or avoided, but they would have less important consequences than in the breast. In gluteal surgery, the main objective of the fat processing technique is to ensure persistence of volume through time.

In this study, 66 procedures were performed on 43 patients by two clinical investigators with the novel technique. The average follow-up period in this study was $>7$ months, which appears to be satisfactory, as fat resorption has been reported to occur within the first 4-6 months in other studies $[15,16]$. As expected, in all cases, some resorption was observed, but total resorption did not occur in any of the cases per the investigators' evaluation. In $95 \%$ of all cases, the resorption was described as minimal or moderate. Additionally, patient satisfaction was high across all the cohorts in this study. In particular, $82.4 \%$ and $87.5 \%$ of the breast augmentation and buttock augmentation patients, respectively, were satisfied with the outcome of only one session of fat grafting. In four cases, under-correction was reported which may lead to consideration of an additional fat grafting session to reach optimal results. This overall high level of satisfaction is in agreement with the data from the literature on breast $[17,18]$ and buttock fat grafting surgery [16].

The complications that occurred in the present cohorts were infection (two cases), liponecrotic cyst (one case), and transitory areolar sensitivity reduction (one case). The infections occurred in two patients of the breast reconstruction cohort. Both of them had a history of radiation therapy. One of them had undergone concomitant scar revision and inframammary fold fixation, which may have played a role in the onset of the infection. The rate of infection (4.9\%) is within the range of data in the literature about fat grafting in irradiated breasts [19]. Liponecrotic cysts are one of the most common complications after large-volume fat grafting, particularly in the breast $[19,20]$, but in the present study, there was only one case of transient liponecrotic cyst across all the cohorts.

Five patients underwent concomitant fat grafting to the face for cosmetic reasons. The fat tissue used in the face was the same as that used in the breast and buttock regions. There were no complications related to the facial fat grafting procedures.

The main limitation of this study lies in the assessment of fat graft survival, which was based purely on qualitative evaluation by the surgeon. Some radiological $[21,22]$ or $3 \mathrm{D}$ photographic methods $[23,24]$ have been proposed and demonstrated as being accurate to assess fat graft survival, but these could not be used in the present study because of its retrospective design. However, fat resorption, as well as patient satisfaction, although qualitative, was prospectively collected as per clinical routine at each center. Furthermore, the literature suggests that, beside the fat graft processing technique used, other factors such as donor area, sex, and age may influence the final quality of the graft. 
However, we did not analyze the impact of these parameters in our study.

On comparing the results of the present series with data from the recent literature, it can be concluded that the novel fat processing technique used in this study is safe and effective for breast and buttock fat grafting surgeries. Further controlled studies are, however, needed to be able to compare its performance with other fat processing techniques.

Author contribution Both authors contributed to the study conception and design, to the preparation of the material, to data collection and analysis, and to the present manuscript.

Funding The study was funded by Groupe SEBBIN SAS.

Data availability The datasets analyzed during the current study are available from the corresponding author on reasonable request.

\section{Compliance with ethical standards}

Conflict of interest Eric Auclair has received speaker and clinical investigator fees from Groupe SEBBIN. Massimo Gianfermi has nothing to disclose.

Ethics approval According to French law, ethics committee approval is not required for retrospective studies.

Consent to participate Patients' consent was obtained.

Consent for publication The authors affirm that human research participants provided informed consent for publication of their data and images in Figs. 3 and 4.

\section{Code availability Not applicable}

Open Access This article is licensed under a Creative Commons Attribution 4.0 International License, which permits use, sharing, adaptation, distribution and reproduction in any medium or format, as long as you give appropriate credit to the original author(s) and the source, provide a link to the Creative Commons licence, and indicate if changes were made. The images or other third party material in this article are included in the article's Creative Commons licence, unless indicated otherwise in a credit line to the material. If material is not included in the article's Creative Commons licence and your intended use is not permitted by statutory regulation or exceeds the permitted use, you will need to obtain permission directly from the copyright holder. To view a copy of this licence, visit http://creativecommons.org/licenses/by/4.0/.

\section{References}

1. Neuber F (1893) Fettransplantation. Bericht über die Verhandlungen der deutschen Gesellschaft für Chirurgie. Zentralbl Chir 22-66

2. Coleman SR (1997) Facial recontouring with lipostructure. Clin Plast Surg 24(2):347-367
3. Raj S, Abu-Ghname A, Davis MJ, Izaddoost SA, Winocour SJ (2020) Safety and regulation of fat grafting. Semin Plast Surg 34(1):59-64

4. Silva-Vergara C, Fontdevila J, Weshahy O, Yuste M, Descarrega J, Grande L (2017) Breast cancer recurrence is not increased with lipofilling reconstruction: a case-controlled study. Ann Plast Surg 79(3):243-248

5. Xue EY, Narvaez L, Chu CK, Hanson SE (2020) Fat processing techniques. Semin Plast Surg 34(1):11-16

6. Conde-Green A, de Amorim NF, Pitanguy I (2010) Influence of decantation, washing and centrifugation on adipocyte and mesenchymal stem cell content of aspirated adipose tissue: a comparative study. J Plast Reconstr Aesthet Surg 63(8):1375-1381

7. Ruan QZ, Rinkinen JR, Doval AF, Scott BB, Tobias AM, Lin SJ, Lee BT (2019) Safety profiles of fat processing techniques in autologous fat transfer for breast reconstruction. Plast Reconstr Surg 143(4):985-991

8. Kang D, Luan J (2018) Fat necrosis after autologous fat transfer (AFT) to breast: comparison of low-speed centrifugation with sedimentation. Aesthet Plast Surg 42(6):1457-1464

9. Chiu WK, Fracol M, Feld LN, Qiu CS, Kim JYS (2019) A comparison of fat graft processing techniques: outcomes in 1,158 procedures in prosthetic breast reconstructions. Plast Reconstr Surg Glob Open 7(11):e2276. https://doi.org/10.1097/GOX. 0000000000002276

10. Rose JG Jr, Lucarelli MJ, Lemke BN, Dortzbach RK, Boxrud CA, Obagi S, Patel S (2006) Histologic comparison of autologous fat processing methods. Ophthalmic Plast Reconstr Surg 22(3):195200

11. Schmitt T, Jabbour S, Makhoul R, Noel W, Reguesse AS, Levan P (2018) Lower body lift in the massive weight loss patient: a new classification and algorithm for gluteal augmentation. Plast Reconstr Surg 141(3):625-636

12. Ulloa M, Coronel Banda M (2017) Scar tissue causing saphenous nerve entrapment: percutaneous scar release and fat grafting. Plast Reconstr Surg Glob Open 5(9):e1495. https://doi.org/10.1097/ GOX.0000000000001495

13. Orholt M, Larsen A, Hemmingsen MN, Mirian C, Zocchi ML, Vester-Glowinski PV, Herly M (2020) Complications after breast augmentation with fat grafting: a systematic review. Plast Reconstr Surg 145(3):530e-537e

14. Zocchi ML, Zocchi L (2017) Large-volume breast fat transfer: technical evolutions and safety aspects based on over 800 cases and 26 years of follow-up. Eur J Plast Surg 40(5):367-382

15. Coleman SR, Saboeiro AP (2007) Fat grafting to the breast revisited: safety and efficacy. Plast Reconstr Surg 119(3):775785; discussion 786-777

16. Murillo WL (2004) Buttock augmentation: case studies of fat injection monitored by magnetic resonance imaging. Plast Reconstr Surg 114(6):1606-1614; discussion 1615-1606

17. Brown AWW, Kabir M, Sherman KA, Meybodi F, French JR, Elder EB (2017) Patient reported outcomes of autologous fat grafting after breast cancer surgery. Breast 35:14-20

18. Cogliandro A, Barone M, Tenna S, Morelli Coppola M, Persichetti P (2017) The role of lipofilling after breast reconstruction: evaluation of outcomes and patient satisfaction with BREAST-Q. Aesthet Plast Surg 41(6): 1325-1331

19. Herly M, Orholt M, Larsen A, Pipper CB, Bredgaard R, Gramkow CS, Katz AJ, Drzewiecki KT, Vester-Glowinski PV (2018) Efficacy of breast reconstruction with fat grafting: a systematic review and meta-analysis. J Plast Reconstr Aesthet Surg 71(12): $1740-1750$

20. Groen JW, Negenborn VL, Twisk JW, Ket JC, Mullender MG, Smit JM (2016) Autologous fat grafting in cosmetic breast augmentation: a systematic review on radiological safety, complications, 
volume retention, and patient/surgeon satisfaction. Aesthet Surg J 36(9):993-1007

21. Choi M, Small K, Levovitz C, Lee C, Fadl A, Karp NS (2013) The volumetric analysis of fat graft survival in breast reconstruction. Plast Reconstr Surg 131(2):185-191

22. Wolf GA, Gallego S, Patron AS, Ramirez F, de Delgado JA, Echeverri A, Garcia MM (2006) Magnetic resonance imaging assessment of gluteal fat grafts. Aesthet Plast Surg 30(4):460-468

23. Herly M, Muller FC, Orholt M, Hansen J, Svaerke S, Hemmingsen MN, Rasmussen BS, Elberg JJ, Drzewiecki KT, Vester-Glowinski
PV (2019) The current gold standard breast volumetry technique seems to overestimate fat graft volume retention in the breast: a validation study. J Plast Reconstr Aesthet Surg 72(8):1278-1284

24. Losken A, Seify H, Denson DD, Paredes AA Jr, Carlson GW (2005) Validating three-dimensional imaging of the breast. Ann Plast Surg 54(5):471-476; discussion 477-478

Publisher's note Springer Nature remains neutral with regard to jurisdictional claims in published maps and institutional affiliations. 